\title{
Effects of changes in temperature (local and central) on plasma fibrinolytic activity
}

\author{
B. DODMAN, W. J. CUNLIFFE, B. E. ROBERTS, AND C. W. BUCHAN
}

From the Departments of Dermatology, Leeds General Infirmary, St James's (University) Hospital, and Harrogate General Hospital, and the Department of Haematology, Leeds General Infirmary

SYNOPSIS The effect of local and whole-body heating and cooling on plasma fibrinolytic activity has been investigated in 59 subjects. An increase in whole-body temperature and both local cooling $\stackrel{N}{\circ}$ and heating increased the fibrinolytic activity. The results demonstrate that the application of $\vec{s}$ local heat or cold will produce a local increase in fibrinolytic activity which is independent of $\stackrel{+}{\infty}$ general factors such as emotion and stress.

Much is known about the physiological factors which influence blood fibrinolytic mechanisms, for example, exercise (Biggs, MacFarlane, and Pilling, 1947; Fearnley and Lackner, 1955) and emotion (MacFarlane, 1947; Ogston, McDonald, and Fullerton, 1962) increase fibrinolytic activity whereas increasing weight reduces fibrinolytic activity (Grace, 1967). In view of our interest in cutaneous vascular disorders and their possible precipitation by a cold environment, eg, Raynaud's phenomenon, we looked further into the effects of temperature on plasma fibrinolysis. In support of this investigation was the observation by Cunliffe and Menon (1969) that infusions of low molecular weight dextran have beneficial effects on the clinical state and blood fibrinolytic activity in patients with Raynaud's phenomenon.

\section{Subjects and Methods}

The investigation consisted of exposing 59 volunteers, 34 females and 25 males aged 17-47 years, to local and whole body heat and cold and measuring the blood fibrinolytic activity before and after exposure. Fibrinolytic activity was measured by the euglobulin lysis time (ELT) which was estimated by the method of von Kaulla (1963) modified by Menon (1967). The investigations were carried out at a constant time, the patients resting and fasting before the test was performed.

Central temperature was measured orally and the skin temperature was measured by a thermister (Brighton Laboratories) placed on the skin.

The effect of cold was investigated in 27 patients Received for publication 10 January 1973. seven of whom were seated, lightly dressed, in a cold room of temperature $4^{\circ} \mathrm{C}$ for 15 minutes. This procedure did not induce shivering. There was no change in central body temperature.

Twenty other subjects placed one arm up to the elbow in a water bath at $4^{\circ} \mathrm{C}$ for four minutes, the appropriate arm remaining at room temperature and acting as a control. A mean decrease in skin temperature of 11.5 degrees was produced in the immersed arm. There was no decrease in general body temperature.

In 32 subjects the effect of heat was investigated: 18 of these subjects had a hot bath $\left(45^{\circ} \mathrm{C}\right)$ for 10 minutes the subjects lying immersed in the bath up to the neck. This produced a significant increase in central body temperature of $2 \cdot 1^{\circ} \mathrm{C}$. Fourteen patients placed one arm in a water bath at $45^{\circ} \mathrm{C}$ for four minutes; this produced an increase in local skin temperature of $6.8^{\circ} \mathrm{C}$ in the immersed arm but in no patient was there any rise in body temperature.

Blood was taken immediately before and immediately after the experiment in all subjects; wherever possible blood was taken from both arms before and after the investigation.

\section{Results}

There was a significant $(\mathrm{P}<0.01)$ increase in $\stackrel{0}{\overparen{D}}$ fibrinolytic activity after exposure to generalized $\stackrel{\oplus}{-}$ heat (fig. 1) but not $(P<0 \cdot 1)$ after exposure to generalized cold (fig. 2). Localized heat produced a significant increase $(P<0.01)$ in fibrinolytic activity in the experimental arm but not $(P<0.4)$ in the control arm (fig. 3). Similar results (fig. 4) were obtained after exposure to localized cold in that 


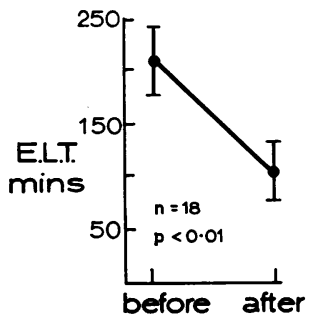

Fig. 1.

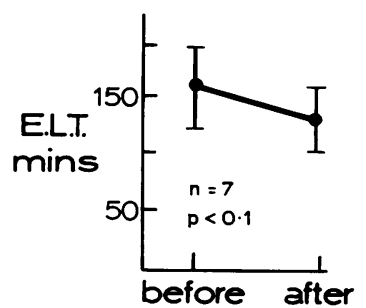

Fig. 2.

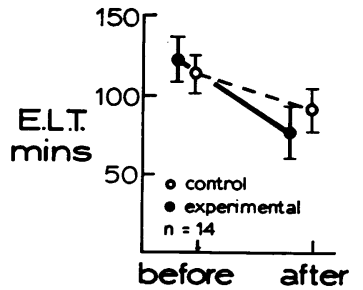

Fig. 3.

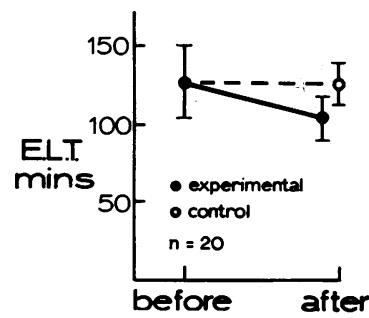

Fig. 4.

Fig. 1 The fibrinolytic activity before and after a hot bath.

Fig. 2 The fibrinolytic activity before and after whole body exposure to cold.

Fig. 3 The fibrinolytic activity after exposure of one arm to hot water.

Fig. 4 The fibrinolytic activity before and after exposure of one arm to cold water.

cold water increased the fibrinolytic activity in the experimental arm $(P<0.05)$ but not in the control arms.

\section{Discussion}

Our findings confirm those of Bedrak, Beer, and Furman (1963) that applied whole body heat will increase plasma fibrinolytic activity.

The mechanism of this increase in fibrinolytic activity with whole body heat is not clear. However, the experiments with local heat demonstrate that there is an increase in fibrinolytic activity in venous blood returning from a localized area of exposure to heat. No significant changes were observed in the control arm in these experiments. This increase, however, may be no more than a reflection of an increased blood flow through the limb resulting in an increased contribution of plasminogen activator from vascular endothelium, the main source of plasminogen activator.

Our observations on the effect of a reduced temperature are more difficult to interpret. Clearly, limited exposure of the body at $4^{\circ} \mathrm{C}$ had no effect on fibrinolytic activity. More severe exposure, such as immersion in a bath of water at $4^{\circ} \mathrm{C}$, may have caused pain and shivering and would have induced other variables. However, local exposure to cold water produced an increased fibrinolytic activity which was confined to the experimental arms, again indicating a local mechanism for the increase of fibrinolytic activity.

It is difficult in experiments based on measurements of fibrinolytic activity to eliminate the effects of stress and emotion. However, this problem has been overcome by applying heat and cold locally to one arm and using the opposite arm as control. It has been demonstrated that both heat and cold cause a local increase in fibrinolytic activity which is not reflected in the circulation as a whole.
These findings are more than just of academic interest, if, as it has been suggested, natural fibrinolysis is a 'built-in' fibrin-clearing mechanism beneficial to the organism. The increase in local fibrinolysis with local cooling could possibly be beneficial to the individual to prevent deposition of fibrin associated with a reduced blood flow. Cash (1966) has demonstrated that most, but not all subjects, increase their fibrinolytic activity with exercise and the possibility that a similar subgroup exists in relationship to change in local temperature merits further investigation. A comparison of this control data with data obtained from patients with Raynaud's phenomenon could be most valuable.

We thank the MRC for a grant to one of us (W.J.C). We also thank Mrs Horner and Mr R. A. Forster for technical help and Mrs L. Lane for secretarial help.

\section{References}

Bedrak, E., Beer, G., and Furman, K. I. (1963). Fibrinolytic activity and heat stress. Israel J. exp. Med., 11, 1-6.

Biggs, R., MacFarlane, R. G., and Pilling, J. (1947). Experimental activity produced by exercise or adrenaline. Lancet, 1, 402-405.

Cash, J. D. (1966). Effect of moderate exercise on the fibrinolytic system in normal young men and women. Brit. med.J., 2, 502.

Cunliffe, W. J., and Menon, I. S. (1969). Blood fibrinolytic activity in diseases of small blood vessels and the effect of low molecular weight dextran. Brit. J. Derm., 81, 220-225.

Fearnley, G. R., and Lackner, R. (1955). The fibrinolytic activity of normal blood. Brit. J. Haemat., 1, 189-198.

Grace, C. S. (1967). The fibrinolytic enzyme system in obesity, the effects of venous occlusion and in vitro activation by surface contact. Clin. Sci., 34, 497-504.

von Kaulla, K. N. (1963). Chemistry of Thrombolysis: Human Fibrinolytic Enzymes, p. 79. Thomas, Springfield, Illinois.

MacFarlane, R. G. (1937). Fibrinolysis following operation. Lancet, 1, 10-12.

Menon, I. S. (1967). Fibrinolysis in citrated and oxalated blood. Lancet, 1, 116.

Ogston, D., McDonald, G. A., and Fullerton, H. W. (1962). The influence of anxiety in tests of blood coagulability and fibrinolytic activity. Lancet, 2, 521-523. 